\title{
Factores asociados a la presencia de neoplasia colorrectal
}

\section{Objetivo}

Determinar los factores de riesgo asociados a neoplasia colorrectal avanzada en personas asintomáticas.

\section{Diseño}

Prospectivo, estudio de corte transversal

Lugar

División de Gastroenterología, Portlans VA Medical Center.

\section{Pacientes}

Un total de 3121 pacientes de 40 a 75 años, asintomáticos, estudiados con colonoscopía completa entre 1994 y 1997.

\section{Evaluación de factores pronósticos}

Las variables examinadas incluyeron historia familiar de cáncer colorrectal en familiares de primer grado, antecedente de colecistectomía, niveles séricos de colesterol, actividad física, tabaquismo, ingesta de alcohol y factores dietéticos.

\section{Medición de resultados principales}

Se efectuó un análisis ajustado* a la edad para calcular la razón de probabilidad (ODDS Ratio) asociada a presentar neoplasia avanzada comparada con no tener pólipos. Se definió como neoplasia avanzada a los adenomas de $10 \mathrm{~mm}$ ó más, a los adenomas vellosos, a los adenomas con displasia de alto grado o al cáncer.

\section{Resultados}

Las variables asociadas a un mayor riesgo se describen en el cuadro 1.

Cuadro 1: variables asociadas a mayor riesgo de neoplasia colorrectal. La única variable asociada a la presencia de pólipos hiperplásicos fue el tabaquismo.

\begin{tabular}{|c|c|}
\hline Variable & ODDs ratio e IC $95 \%$ \\
\hline Historia familiar & $1,66(1,16$ a 2,35$)$ \\
\hline Tabaquismo & $1,85(1,33$ a 2,58$)$ \\
\hline Ingesta de alcohol & $1,02(1,01$ a 1,03$)$ \\
\hline Ingesta de cereales & $0,95(0,91$ a 0,99$)$ \\
\hline Consumo de vitamina D & $0,94(0,90$ a 0,99$)$ \\
\hline Consumo de antinflamatorios no esteroideos & $0.66(0,48$ a 0,91$)$ \\
\hline
\end{tabular}

\section{Conclusiones}

Los resultados confirman el riesgo asociado a neoplasias avanzadas de varios factores y proveen racionalidad a las estrategias de prevención primaria y secundaria del cáncer colorrectal.

\section{Comentario}

La originalidad de este estudio es su diseño de corte transversal y el hecho de que todos los pacientes tuvieron una evaluación endoscópica completa del colon. Una limitación del mismo es que el $97 \%$ de la población correspondió al sexo masculino, por lo que se requeriría mayor evidencia para poder trasladar estos resultados a la población femenina. Por otra parte, el tipo de lesión estudiada (neoplasia avanzada) agrupa diversos tipos de pólipos que tendrían una mayor asociación con el desarrollo de cáncer colorrectal, aunque debe recordarse que en muchos de estos pacientes nunca progresarán (la secuencia pólipo-cáncer sólo se efectiviza en el $5 \%$ de las lesiones, considerando todos los pólipos en general).

El presente estudio confirma la asociación de diferentes variables con las neoplasias avanzadas colorrectales. La relación entre la ingesta grasa y de fibras ha sido investigada por numerosos autores con conclusiones encontradas, probablemente por el diferente diseño de estudio o por las diferentes variables propias de la población estudiada (edad, sexo, raza, etc).

El presente estudio encuentra una acción protectora de la ingesta de fibras que no ha podido ser demostrada en estudios de intervención en pacientes con pólipos previos seguidos durante tres a cuatro años'. La ingesta de antiinflamatoiros no esteroideos (AINE) también se asoció a un menor riesgo, aunque los potenciales efectos adversos de estas drogas hace que no sean recomendables para la prevención. También por primera vez se demuestra un efecto benéfico de la vitamina $D$.

El estudio confirma una vez más la asociación entre los antecedentes familiares y el cáncer colorrectal. Debe recordarse que este riesgo se incrementa con el número de familiares afectados, la cercanía de los mismos y la edad de afectación. Toda persona con dos familiares de primer grado con cáncer colorrectal o con un familiar de primer grado afectado antes de los 50 años, debería ser asesorado por un grupo especializado.

Los resultados del presente estudio también avalan las recomendaciones actuales de tratar a las personas con pólipos hiperplásicos en forma similar a los pacientes sin pólipos.

\section{Conclusiones del comentador}

Se confirma la acción protectora de las fibras y el riesgo elevado en personas con antecedentes familiares de cáncer colorrectal.

Carlos Vaccaro [ Sección de Ciencia Colorrectal, Hospital Italiano de Buenos Aires. ]

Vaccaro C.Factores asociados a la presencia de neoplasia colorrectal.Evid. actuel. práct. ambul 2004;7:139.Comentado de:Lieberman D, Prindiville S, Weiss $\mathrm{D}$ et al. Risk factors for advanced colonic neoplasia and hiperplastic polyps in asintomático individuals. JAMA 2003 ; vol 290 nํ $22,2959-2967$

\section{Referencias}

1.Albert DS, Martinez ME, Roe DJ et al. Lack of effect of high-fiber ceral supplement on the recurrent of colorectal adenomas. N Eng J Med 2000;342:1156-1162) 